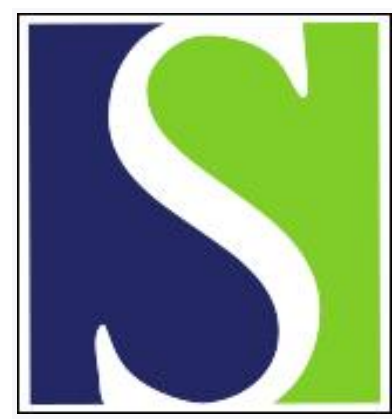

Scand J Work Environ Health 2015;41(1):94-101

https://doi.org/10.5271/sjweh.3466

Published online: 07 Nov 2014, Issue date: 01 Jan 2015

Neurological outcomes associated with low-level manganese exposure in an inception cohort of asymptomatic welding trainees

by Baker MG, Criswell SR, Racette BA, Simpson CD, Sheppard L, Checkoway $\mathrm{H}$, Seixas NS

This is the first manuscript to explore longitudinal measures of the effects on central nervous system related to low-levels of manganese $(\mathrm{Mn})$ exposure in an inception cohort of asymptomatic welding trainees. We document significant changes in T1 MRI related to low-level exposure, before clinical deficits manifest. This manuscript uses longitudinal data to elucidate a learning effect in neurological measures.

Affiliation: Department of Environmental and Occupational Health Sciences, 4225 Roosevelt Way NE, Suite 100, Seattle, WA 98105, USA. bakermg@uw.edu

Key terms: biomarker of effect; biomarker of exposure; effect; exposure; grooved pegboard; learning effect; manganese; manganese exposure; MRI; neurological outcome; UPDRS3; welder; welding trainee

This article in PubMed: www.ncbi.nlm.nih.gov/pubmed/25380186

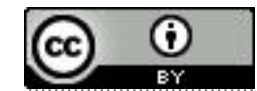




\title{
Neurological outcomes associated with low-level manganese exposure in an inception cohort of asymptomatic welding trainees
}

\author{
by Marissa G Baker, MS, ${ }^{1}$ Susan R Criswell, MD, ${ }^{2}$ Brad A Racette, MD, ,2, 3 Christopher D Simpson, PhD, ${ }^{1}$ \\ Lianne Sheppard, PhD, ${ }^{1,4}$ Harvey Checkoway, PhD, ${ }^{5}$ Noah S Seixas, PhD ${ }^{1}$
}

\begin{abstract}
Baker MG, Criswell SR, Racette BA, Simpson CD, Sheppard L, Checkoway H, Seixas NS. Neurological outcomes associated with low-level manganese exposure in an inception cohort of asymptomatic welding trainees. Scand J Work Environ Health. 2015;41(1):94-101. doi:10.5271/sjweh.3466
\end{abstract}

Objective Long-term, high-level exposure to manganese (Mn) is associated with impaired central nervous
system (CNS) function. We quantitatively explored relations between low-level Mn exposure and selected neu-
rological outcomes in a longitudinal inception cohort of asymptomatic welder trainees.
Methods Welders with no previous occupational Mn exposure were observed approximately every three
months over the course of the five-quarter traineeship. Fifty-six welders were assessed for motor function using
the Unified Parkinson Disease Rating Scale motor subsection part 3 (UPDRS3) and Grooved Pegboard tests.
A subset of 17 also had MRI scans to assess T1-weighted indices. Personal exposure to Mn in welding fume
was quantitatively assessed during the study period using a mixed model to obtain estimates of subject-specific
exposure level by welding type. These estimates were summed to estimate cumulative exposure at the time of
each neurological outcome test.

Results When adjusting for possible learning effects, there were no associations between cumulative exposure and UPDRS3 score or Grooved Pegboard time. T1-weighted indices of the basal ganglia (caudate, anterior putamen, posterior putamen, and combined basal ganglia, but not the pallidal index) exhibited statistically significant increases in signal intensity in relation to increased cumulative Mn exposure.

Conclusions This study demonstrates that $\mathrm{T} 1$-weighted changes can be detected in the brain even at very low levels of exposure among humans before any clinically evident deficits. This suggests that with continued followup we could identify a T1 threshold of toxicity at which clinical symptoms begin to manifest.

Key terms biomarker of effect; biomarker of exposure; effect; exposure; grooved pegboard; learning effect; MRI; UPDRS3; welder.

Elevated exposure to manganese (Mn) has long been an occupational health concern; excess $\mathrm{Mn}$ in the body crosses the blood-brain barrier, accumulates in the brain, and can cause adverse neurological health effects $(1,2)$. Manganism is a syndrome characterized by parkinsonism features (bradykinesia, rigidity, postural instability, tremor), dystonia, and cognitive dysfunction, clinical features also common to idiopathic Parkinson's disease (3).

Welders typically experience 8-hour mean personal breathing zone $\mathrm{Mn}$ concentrations ranging from $<0.02->1.0 \mathrm{mg} / \mathrm{m}^{3}$, depending on welding process and control methods (4-7). The American Conference of Governmental Industrial Hygienists' (ACGIH) 8-hour time-weighted average threshold limit value (TWA TLV) for $\mathrm{Mn}$ in total inhalable dust was recently reduced to $0.1 \mathrm{mg} / \mathrm{m}^{3}$ and the respirable TLV was reduced to 0.02 $\mathrm{mg} / \mathrm{m}^{3}$, based on neurological outcomes seen in workers exposed to low levels of Mn (8). Although welding fume is almost entirely respirable, other metalworking tasks commonly done by welders generate larger, inhalable particles. However, the Occupational Safety and Health Administration's Permissible Exposure Limit (OSHA

1 Department of Environmental and Occupational Health Sciences, University of Washington, Seattle, WA, USA.

2 Department of Neurology, Washington University School of Medicine, St. Louis, MO, USA.

3 Faculty of Health Sciences, School of Public Health, University of Witwatersrand, Johannesburg, South Africa.

4 Department of Biostatistics, University of Washington, Seattle, WA, USA

5 Department of Family and Preventive Medicine, University of California San Diego, San Diego, California, USA.

Correspondence to: Marissa G Baker, Department of Environmental and Occupational Health Sciences, 4225 Roosevelt Way NE, Suite 100, Seattle, WA 98105, USA. [E-mail: bakermg@uw.edu] 
PEL) for $\mathrm{Mn}$ in total inhalable dust of $5.0 \mathrm{mg} / \mathrm{m}^{3}$ (ceiling) is the only enforceable Mn standard in the United States. In Europe, the European Commission Scientific Committee on Occupational Exposure Limits (SCOEL) recommends an 8-hour TWA of $0.2 \mathrm{mg} / \mathrm{m}^{3}$ for $\mathrm{Mn}$ in the inhalable fraction and $0.05 \mathrm{mg} / \mathrm{m}^{3}$ for $\mathrm{Mn}$ in the respirable fraction, though enforceable standards would vary between European countries (9).

Manganism has historically been associated with long-term, high levels of occupational exposure to $\mathrm{Mn}$, yet neurological effects have been observed at Mn levels below the OSHA PEL and closer to the ACGIH TLV or SCOEL recommended 8-hour TWA (10-12). Recently, Laohaudomchok et al (13) reported parkinsonian effects among welders who experience low Mn exposures (median: $0.013 \mathrm{mg} / \mathrm{m}^{3}$ ). Ellingsen et al (14) found welders with a mean Mn exposure of $0.21 \mathrm{mg} / \mathrm{m}^{3}$ to have poorer performance than unexposed referents on Grooved Pegboard, Finger Tapping, and Simple Reaction Time tests. In contrast, among both mineworkers and smelter workers exposed to Mn, Myers et al $(15,16)$ found no relationship between Mn exposure and nervous system effects, even at levels above the ACGIH TLV.

While neurological function tests, such as UPDRS3 and Grooved Pegboard, are classified as biomarkers of Mn effect, T1-weighted magnetic resonance images (MRI) have been utilized as a biomarker of $\mathrm{Mn}$ in-vivo brain exposure. $\mathrm{Mn}$ is a paramagnetic element that strongly influences the magnetic resonance properties of surrounding tissues. Mn shortens tissue T1 relaxation times resulting in increased signal intensity detectible on T1-weighted imaging. Human studies have confirmed the intensity of the T1 pallidal signal correlates with blood Mn levels and cumulative exposure to $\mathrm{Mn}$, but it may not be as accurate at low levels of chronic exposure (17-19). A recent paper by Criswell et al (20) found intensity changes in the caudate and putamen to be better markers of cumulative exposure. In this study we attempt to evaluate caudate, putamen, and pallidal T1 signal as markers of low-level Mn exposure in a longitudinal study of welder trainees.

Many tests exist to assess neurotoxicity associated with $\mathrm{Mn}$ exposure, both specific (ie, functional imaging techniques, neuropsychiatric testing for domains of memory) and general (ie, some tests of mood, dexterity), that have been used either singularly or as part of a battery $(3,21-23)$. Epidemiologic studies assessing neurological outcomes associated with Mn exposure among welders and other occupationally exposed groups are most commonly cross-sectional. Although non-exposed referent groups are frequently included, to our knowledge no prior studies have included pre-exposure baseline measurements of CNS function on a well-characterized Mn-exposed occupational cohort. While a longitudinal inception cohort study of neurological function allows for individuals to serve as their own controls, the perfor- mance-based tests also raise the possibility of learning effects, which can obscure changes over time (24).

In this study, we employed three methods to longitudinally assess CNS function in a cohort of previously unexposed welders exposed to low levels of $\mathrm{Mn}$ : (i) the Grooved Pegboard examination to assess dexterity and fine motor control (25), (ii) UPDRS3 for parkinsonian signs such as rest and postural tremor, bradykinesia, and gait disturbance (26), and (iii) T1-weighted brain MRI, an in-vivo measure of Mn exposure $(20,27)$. The purpose of this manuscript is to explore neurological outcomes associated with low-level cumulative exposures to $\mathrm{Mn}$ in a longitudinal cohort of asymptomatic welder trainees.

\section{Methods}

\section{Occupational setting and study population}

Subjects included 56 welder trainees enrolled in a 5 -quarter welding training program at a technical college in Washington State who joined our cohort prior to occupational exposure to Mn. All 56 enrolled subjects underwent longitudinal UPDRS3 and Grooved Pegboard tests, and 17 underwent repeat MRI measures. Details of the cohort study and the welding traineeship have been previously described (28). In accordance with the Helsinki Declaration, the University of Washington (UW) Institutional Review Board and UW Human Research Protection Office reviewed and approved all study protocols, and subjects provided written informed consent. Data collection for the study began in April 2011 and was completed in June 2013.

Upon entry to the study, and at the end of each academic quarter (approximately ten weeks), all subjects completed the Grooved Pegboard test and UPDRS3 examination. Similarly, upon entry and at the end of each academic quarter, those subjects enrolled in the MRI sub cohort were transported to UW Medical Center (UWMC, Seattle, WA, USA) for MRI scans. On completion of the study, co-investigators at Washington University (WU, St Louis, MO, USA) interpreted all UPDRS3 examinations and MRI scans, which had been stripped of any time- or subject-identifying information.

\section{Grooved Pegboard}

Trained research staff administered the Grooved Pegboard (Lafayette Instrument Evaluation, West Lafayette, IN, USA) examination on each subjects' dominant and non-dominant hand, following the procedure outlined by the Grooved Pegboard's user's manual $(25,29)$. A higher score (longer time to complete the test) indicates reduced dexterity and fine motor control. 


\section{Unified Parkinson Disease Rating Scale, motor subsection part 3}

Each subject was videotaped completing the UPDRS3 examination, except for rigidity. Videos were rated by a movement disorders specialist blinded to the exposure and clinical status of the subject $(26,30)$. If the video quality did not allow an individual item to be graded, that subject's total score was not able to be calculated, and thus was not included in analyses. Five UPDRS3 examinations from five different subjects were missing a measure of tremor, likely at random and not affecting our outcome analyses.

\section{Magnetic resonance imaging}

Subjects interested in participating, and with no contraindications to MRI, were enrolled in the MRI sub cohort and transported to UW Diagnostic Imaging Sciences Center at the end of the workday where MRI scans were conducted on a 3T Philips Achieva MR System. Structural anatomic scans included a T1-weighted sagittal, magnetization-prepared rapid gradient echo [MPRAGE; repetition time $(\mathrm{TR})=20.0 \mathrm{~ms}$; inversion time $(\mathrm{TI})=1000$ $\mathrm{ms}$, echo time $(\mathrm{TE})=3.14 \mathrm{~ms}$, flip angle $=8^{\circ}, 0.9 \times 0.9 \times 0.9$ $\mathrm{mm}$ voxels] and, as is standard, T2-weighted indices were also measured. However, results from T2-weighted imaging are not informative in relation to $\mathrm{Mn}$ exposure and are not presented.

A reviewer blinded to the clinical and exposure status of the subject outlined volumes of interest (VOI) on individual MR images including bilateral caudate, globus pallidus, anterior putamen, posterior putamen, and then calculated a combined basal ganglia as the average signal of all the above VOI. The intensity of the signal on the T1 weighted image in the VOI was compared to standard frontal white matter control regions by calculating an intensity index (see equation 1) for each subject. Regional indices were calculated from the T1 MPRAGE images as previously described for the pallidal index (PI) (31).

(equation 1)

Intensity index

$=\left[\frac{(\text { Left VOI }+ \text { Right VOI })}{\text { (Left white matter control region }+ \text { Right white matter control region })}\right] \times 100$

All MRI were screened for neurological abnormalities at UW prior to interpretation by WU co-investigators.

\section{Estimating manganese exposure in air}

The subject was enrolled in the study four times during each quarter and fitted with a personal air pump (SKC AirChek XR4000, Eighty Four, PA, USA) with an attached pre-weighed $37 \mathrm{~mm} 0.8 \mu \mathrm{m}$ pore mixed cellulose ester filter hung in their breathing zone, outside the welding helmet. The pumps operated at a flow of $2.0 \mathrm{~L} / \mathrm{min}$, which was measured at the beginning and end of each full-shift sampling period. Subjects completed an exposure questionnaire to assess type of welding, use of respiratory protection, and confounding sources of Mn exposure. Air filters were analyzed gravimetrically for total particulate mass, then digested and analyzed for trace metals by inductively coupled plasma mass spectrometry (ICP-MS) at the UW Environmental Health Laboratory (32). Reporting limits for Mn ranged from $0.01-0.03 \mu \mathrm{g}$, depending on analysis-batch-specific field blanks, and were based on three times the standard deviation of the blanks, which were treated the same as the samples in the field. No air samples fell below the reporting limit.

We calculated 8-hour TWA Mn concentrations, lntransformed the concentrations, and a mixed model was fit to obtain estimates of exposure level by welding type (fixed effect), adjusted for subject (random effect). These estimates were used to predict 8-hr TWA Mn exposure levels, based on the type of welding subjects self-reported to be doing each day of their enrollment. Weekends, vacation days, and days the subjects were absent (as ascertained from school attendance records) were coded as zero exposure. On days when a neurological function test occurred, all preceding predicted daily exposures were summed to create a predicted cumulative exposure from time of entry into the program to the day of the neurological function test, in units of $\mathrm{mg} / \mathrm{m}^{3}$-day.

\section{Statistical analysis}

The associations between predicted cumulative exposure at the time of the test and each neurological outcome of interest were assessed using longitudinal linear mixedeffects models allowing for subject as a random effect. For UPDRS3, the neurological outcome of interest was the total UPDSR 3 score. As gender is a well-established effect modifier for the Grooved Pegboard $(33,34)$, and only four females were enrolled in our study, pegboard models of dominant hand time are only presented for males (number of subjects $=52$ ).

There was only one female in the MRI sub cohort, but removing her four scans from the mixed models did not affect the regression coefficients relating exposure and outcome, thus she is included in all MRI models. While several covariates were considered in the mixed models (including smoking status, alcohol drinker, prior self-reported loss of consciousness, self-reported respirator use, and age at baseline), the only covariate significant in any model was age at baseline, which was found to contribute significantly to the Grooved Pegboard models and some of the MRI models. Thus, all models were adjusted for subject age at baseline. 
Because subjects underwent repeat measures of UPDRS3 and Pegboard over fairly short time periods (mean time between examinations was 66 days), we hypothesized changes in score that appear to be associated with cumulative exposure may in fact be influenced by a learning effect. Therefore, in addition to crude models unadjusted for a learning effect, we also adjusted the UPDRS3 and Pegboard models to control for a potential learning effect. To accomplish this, we corrected the existing models for three predictors, based on guidance from McKnight et al (35): number of previous tests (continuous), months since previous test (continuous), and a binary indication of whether or not it was the first test (first test $=0$, subsequent tests $=1$ ). All data analysis was done at UW using Stata 12 (Stata Corp LP, College Station, TX, USA).

\section{Results}

Demographic characteristics for the entire welding cohort and MRI sub cohort are summarized in table 1. The MRI sub cohort was similar to the entire cohort. Measured 8-hr TWA Mn concentrations $(\mathrm{N}=600)$ ranged from $0.2-208 \mu \mathrm{g} / \mathrm{m}^{3}$ [geometric mean 16.5 , geometric standard deviation (GSD) 3.4] Only 4.5\% of all samples $(\mathrm{N}=27)$ exceeded the ACGIH inhalable TLV of $0.1 \mathrm{mg} /$ $\mathrm{m}^{3}$, but assuming $\mathrm{Mn}$ in welding fume is primarily in the respirable range (36), $51.8 \%$ of all samples $(\mathrm{N}=211)$ exceeded the ACGIH respirable TLV of $0.02 \mathrm{mg} / \mathrm{m}^{3}$.

Predicted 8-hr TWA Mn concentrations, which were modeled from the measured 8-hr TWA Mn concentrations, ranged from $4.1-68.6 \mu \mathrm{g} / \mathrm{m}^{3}$ (geometric mean 15.7, GSD 2.2). The modeled exposure values were subsequently used to estimate cumulative exposure.

Table 2 summarizes the neurological outcomes for all time points. None of the pegboard times were outside of the typical reference ranges, based on age and gender $(29,34,37)$. Similarly, none of the UPDRS3 scores were indicative of definite or probable parkinsonism $(>15)$, though $\mathrm{N}=14(5.3 \%)$ of the UPDRS3 scores were $>6$, a mildly elevated score (26). The average subject underwent 3.8 [standard deviation (SD) 1.7] Grooved Pegboard tests (range 1-7) and 3.7 (SD 1.6) UPDRS3 examinations (range 1-7). The average subject in the MRI sub cohort underwent 3.7 (SD 1.6) MRI scans (range 1-7).

Table 3A shows coefficients of association between predicted cumulative exposure and time-to-complete the pegboard test for males using their dominant hand. For males of a similar age completing the pegboard test with their dominant hand, each $1 \mathrm{mg} / \mathrm{m}^{3}$-day increase in cumulative exposure is associated with, on average a -0.60 second [ $95 \%$ confidence interval $(95 \% \mathrm{CI})-1.00$ -0.21 f faster completion of the test. When adjusting this model to control for a learning effect, the coefficient of association between cumulative exposure and time to complete the pegboard test was similar $(-0.68,95 \%$ CI -1.6-0.27), however the $95 \%$ confidence interval indicates that the unadjusted negative association was influenced by a learning effect.

Similar relationships were seen for males using their non-dominant hand (not shown). In both unadjusted and adjusted pegboard models, age at baseline was a significant contributor to the model, and when adjusting for a learning effect, an increase in months between tests resulted in a slight but significant increase in time to complete the test, an average of 1.22 seconds slower (95\% CI 0.27-1.83).

Table 3B shows coefficients of association between predicted cumulative exposure and total UPDRS3 score, both adjusted for a learning effect and unadjusted. In the unadjusted model, a $1 \mathrm{mg} / \mathrm{m}^{3}$-day increase in cumulative exposure was associated with a -0.12 point lower score (95\% CI -0.21-0.04). However, in the adjusted model, the association between UPDRS3 score and cumulative exposure indicates that this test was also influenced by a learning effect.

Table 4 shows the associations between cumulative exposure and MRI outcomes. Among the MRI outcomes, caudate, anterior putamen, posterior putamen, and combined basal ganglia $\mathrm{T} 1$ indices were all increased significantly in relation to increased cumulative $\mathrm{Mn}$ exposure. The T1 PI did not show any changes associated with low level cumulative exposure. For subjects of a similar age, a $1 \mathrm{mg} / \mathrm{m}^{3}$-day increase in cumulative $\mathrm{Mn}$ exposure was associated with, on average, a caudate $\mathrm{T} 1$ index with an increased signal intensity of 0.31 (95\% CI $0.14-0.48)$, an anterior putamen $\mathrm{T} 1$ index with an average increased signal intensity of 0.26 ( $95 \%$ CI $0.10-0.41)$, a posterior putamen $\mathrm{T} 1$ index with an average increased signal intensity of 0.22 (95\% CI 0.08-0.36), and a combined basal ganglia T1 index with an average increased signal intensity of 0.18 ( $95 \%$ CI $0.07-0.30)$. These average increases correspond to a $0.4 \%$ increase from the baseline mean caudate $\mathrm{T} 1$ index, a $0.3 \%$ increase from the baseline mean anterior putamen $\mathrm{T} 1$ index, and a $0.2 \%$ increase from both the baseline mean posterior putamen and combined basal ganglia $\mathrm{T} 1$ indices.

One subject exhibited a large change between their penultimate and last MRI, the only instance of at least a $10 \%$ change between two subsequent scans for any $\mathrm{T} 1$ measures among any of the subjects. The findings were not materially changed when sensitivity analyses were performed excluding this subject.

\section{Discussion}

To our knowledge, this is first study to longitudinally explore changes to the CNS associated with Mn exposure 
Table 1. Subject demographics. [Mn=manganese; $M R I=$ magnetic resonance imaging; $S D=$ standard deviation; UPDRS3= Unified Parkinson Disease Rating Scale motor subsection part 3.]

\begin{tabular}{|c|c|c|c|c|c|c|c|c|c|c|}
\hline & \multicolumn{5}{|c|}{ UPDRS3/Pegboard cohort } & \multicolumn{5}{|c|}{ MRI subcohort } \\
\hline & $\begin{array}{c}\text { Subjects } \\
(\mathrm{N})\end{array}$ & Mean & $\%$ & SD & Range & $\begin{array}{c}\text { Subjects } \\
(\mathrm{N})\end{array}$ & Mean & $\%$ & SD & Range \\
\hline Age at baseline (years) & 56 & 28.0 & & 9.6 & $18-55$ & 17 & 24.6 & & 7.3 & $18-41$ \\
\hline Smoking (pack-years) & 56 & 3.7 & & 6.6 & $0-36$ & 17 & 1.3 & & 1.8 & $0-6$ \\
\hline $\begin{array}{l}\text { Predicted cumulative } \mathrm{Mn} \\
\text { exposure at last test (mg/m³-days a) }\end{array}$ & 56 & 4.4 & & 2.6 & $0.01-10.5$ & 17 & 3.8 & & 2.8 & $0.03-8.8$ \\
\hline UPDRS3 tests (number) & 56 & 3.7 & & 1.6 & $1-7$ & 17 & 3.8 & & 1.6 & $1-7$ \\
\hline Pegboard tests (number) & 52 & 3.8 & & 1.7 & $1-7$ & 17 & 4.0 & & 1.8 & $1-7$ \\
\hline MRI scans (number) & & & & & & 17 & 3.7 & & 1.6 & $1-7$ \\
\hline \multicolumn{11}{|l|}{ Categorical smoking status } \\
\hline Never & 23 & & 41 & & & 8 & & 47 & & \\
\hline Current & 21 & & 38 & & & 6 & & 35 & & \\
\hline Previous & 12 & & 21 & & & 3 & & 18 & & \\
\hline Drinks alcohol (yes) & 39 & & 70 & & & 12 & & 71 & & \\
\hline Respirator user & 14 & & 25 & & & 4 & & 24 & & \\
\hline Previous head injury (yes) & 31 & & 55 & & & 10 & & 59 & & \\
\hline Male & 52 & & 93 & & & 16 & & 94 & & \\
\hline
\end{tabular}

a Includes all days enrolled in the program, including zero-exposure days.

Table 2. Neurological outcome descriptives. [MRI=magnetic resonance imaging; SD=standard deviation; UPDRS3= Unified Parkinson Disease Rating Scale motor subsection part 3.]

\begin{tabular}{lccccccc}
\hline Pegboard (sec) & Tests (N) & Subjects (N) & Mean & Overall SD & Within SD a & Between SD & Range \\
\hline Males (dominant) & 199 & 52 & 62.9 & 9.5 & 4.5 & 7.6 & $45-112$ \\
$\quad \begin{array}{l}\text { Males (non-dominant) } \\
\text { UPDRS3 score }\end{array}$ & 199 & 52 & 67.0 & 11.4 & 4.8 & 9.5 & $47-112$ \\
$\quad$ Overall total & 205 & 56 & 2.1 & 2.1 & 1.1 & 1.8 & $0-9$ \\
$\quad$ MRI score & & & & & & & \\
$\quad$ Caudate T1 & 63 & 17 & 86.2 & 2.9 & 1.0 & 2.4 & $80.2-96.8$ \\
Anterior putamen T1 & 63 & 17 & 90.2 & 3.0 & 0.9 & 2.7 & $85.2-98.5$ \\
Posterior putamen T1 & 63 & 17 & 94.6 & 3.4 & 1.0 & 3.2 & $87.4-101.4$ \\
Basal ganglia T1 & 63 & 17 & 94.7 & 2.8 & 0.8 & 2.5 & $89.1-100.0$ \\
Pallidal Index T1 & 63 & 17 & 108.0 & 2.7 & 1.2 & 2.3 & $99.9-113.8$ \\
\hline
\end{tabular}

${ }^{a}$ Average within-subject standard deviation calculated only using those subjects with at least $\mathrm{N}=2$ tests, which was 47 male pegboard subjects, 51 UPDRS3 subjects, and $15 \mathrm{MRI}$ subjects.

among subjects who (i) were asymptomatic at baseline, (ii) had no prior occupational exposure to $\mathrm{Mn}$, and (iii) had known baseline measures. The three methods of assessing neurological outcomes we selected allowed us to evaluate markers of in-vivo Mn exposure (MRI), clinical measures of parkinsonism (UPDRS3), and clinical measures of fine motor skill/dexterity (Grooved Pegboard). As a condition of entry into the study, all subjects were deemed asymptomatic, as assessed by a health screening questionnaire. Baseline UPDRS3 and Grooved Pegboard examinations confirmed subjects to be clinically normal, as UPDRS3 scores were within the normal range (26), and Grooved Pegboard completion times were within typical age- and gender-specific reference ranges. Twenty-five percent of the cohort self-reported using respirators. However, field research staff observed very poor respirator practices; for example, no fit testing or respiratory protection training was provided on site, subjects failed to regularly change cartridges, and frequently wore them inconsistently or incorrectly. Thus, even though respirators were used, the degree of protection would not be as much as expected under ideal circumstances. Nevertheless, we tested the impact of respiratory protection on the exposure-response relationship and no effect was observed on either the outcome or the relationship between the exposure and outcome.

Unadjusted findings from the UPDRS3 and Grooved Pegboard mixed models indicated a tendency for pegboard time and UPDRS3 score to be inversely related to cumulative exposure. However, when adjusting for a learning effect, these relationships were no longer apparent. Time since enrolling in the study and cumulative exposure are, unsurprisingly, highly correlated (Pearson's r=0.84). Thus, being able to parse out the effects of increased Mn exposure on Pegboard time or UPDRS3 score from the effects of repeat tests over a fairly short time period in a longitudinal study is challenging. However, it is apparent for both pegboard and 
Table 3. Association of $(A)$ dominant-hand pegboard times and (B) Unified Parkinson Disease Rating Scale motor subsection part 3 (UPDRS3) scores with cumulative exposure, both unadjusted and adjusted for a learning effect. [SD=standard deviation; 95\% $\mathrm{Cl}=95 \%$ confidence interval.]

\begin{tabular}{|c|c|c|c|c|c|c|}
\hline \multirow[t]{2}{*}{ A. Pegboard } & \multicolumn{3}{|c|}{$\begin{array}{l}\text { Unadjusted for } \\
\text { learning effect }\end{array}$} & \multicolumn{3}{|c|}{$\begin{array}{l}\text { Adjusted for } \\
\text { learning effect }\end{array}$} \\
\hline & $S D^{a}$ & B & $95 \% \mathrm{Cl}$ & SD & B & $95 \% \mathrm{Cl}$ \\
\hline \multicolumn{7}{|l|}{ A. Pegboard } \\
\hline $\begin{array}{l}\text { Cumulative } \\
\text { exposure }\end{array}$ & & -0.60 & $-1.00--0.21$ & & -0.68 & $-1.6-0.27$ \\
\hline Age at baseline & & 0.26 & $0.05-0.47$ & & 0.26 & $0.05-0.47$ \\
\hline Previous tests (N) & & & & & -0.08 & $-1.6-1.4$ \\
\hline $\begin{array}{l}\text { Months since previ- } \\
\text { ous test }\end{array}$ & & & & & 1.22 & $0.27-1.83$ \\
\hline Not first test & & & & & -3.1 & $-6.4-0.20$ \\
\hline Within subject & 5.8 & & $5.2-6.5$ & 5.8 & & $5.1-6.5$ \\
\hline Between subject & 6.7 & & $5.2-8.5$ & 6.7 & & $5.3-8.6$ \\
\hline \multicolumn{7}{|l|}{ B. UPDRS3 } \\
\hline $\begin{array}{l}\text { Cumulative } \\
\text { exposure }\end{array}$ & & -0.12 & $-0.21--0.04$ & & -0.01 & $-0.22-0.19$ \\
\hline Age at baseline & & 0.03 & $-0.02-0.08$ & & 0.03 & $-0.02-0.08$ \\
\hline Previous tests (N) & & & & & -0.21 & $-0.55-0.14$ \\
\hline $\begin{array}{l}\text { Months since } \\
\text { previous test }\end{array}$ & & & & & 0.061 & $-0.12-0.27$ \\
\hline Not first test & & & & & -0.15 & $-0.92-0.62$ \\
\hline Within subject & 1.3 & & $1.2-1.5$ & 1.3 & & 1.2-1.5 \\
\hline Between subject & 1.6 & & $1.3-2.0$ & 1.6 & & $1.3-2.0$ \\
\hline
\end{tabular}

a From mixed effects restricted maximum likelihood (REML) regression.

UPDRS3 that, over the relatively short time periods we repeatedly administered these tests, there were no meaningful changes with increased exposure to airborne $\mathrm{Mn}$. In contrast, we did observe hypothesized associations of cumulative exposure with MRI patterns, which are not subject to learning or time effects.

Despite exposure at or near the ACGIH respirable $\mathrm{TLV}$, there was an apparent increase in T1 signal intensities for several parts of the basal ganglia (ranging from a $0.2-0.4 \%$ increase over the mean) indicative of in-vivo effects associated with $\mathrm{Mn}$ exposure. Thus, it appears that even at very low levels of occupational exposure, changes associated with $\mathrm{Mn}$ exposure are apparent via MRI techniques, before clinical measures (such as those assessed via UPDRS3 and Grooved Pegboard) manifest, or can overcome influences from time and learning.

Our results corroborate with those reported by Criswell et al (20) among career professional welders, in which the caudate, putamen, and basal ganglia indices all demonstrated stronger correlations with $\mathrm{Mn}$ exposure than the PI, especially at low levels of Mn exposure. Animal and human studies demonstrated $\mathrm{Mn}$ deposition throughout all parts of basal ganglia $(38,39)$. These studies and our results suggest that while earlier studies have focused on the pallidum as the primary target of Mn exposure (as characterized by the PI), the caudate and putamen may be the better regions to serve as biomarkers of Mn exposure.
Table 4. Association of $\mathrm{T} 1$ weighted magnetic resonance imaging (MRI) indices with cumulative exposure, adjusted for age at baseline. [ $95 \% \mathrm{Cl}=95 \%$ confidence interval; $\mathrm{SD}=$ standard deviation.]

\begin{tabular}{lcccc}
\hline $\begin{array}{l}\text { MRI score / } \\
\text { (mg/m³-days) }\end{array}$ & $B$ & $95 \%$ Cl & $\begin{array}{c}\text { Within } \\
\text { SD }\end{array}$ & $\begin{array}{c}\text { Between } \\
\text { SD }\end{array}$ \\
\hline Caudate T1 & 0.31 & $0.14-0.48$ & 1.5 & 1.8 \\
Anterior putamen T1 & 0.25 & $0.10-0.41$ & 1.3 & 2.3 \\
Posterior putamen T1 & 0.22 & $0.08-0.36$ & 1.2 & 2.9 \\
Basal ganglia T1 & 0.18 & $0.06-0.29$ & 1.0 & 2.3 \\
Pallidal Index T1 & -0.04 & $-0.22-0.14$ & 1.6 & 2.3 \\
\hline
\end{tabular}

${ }^{a}$ From mixed effects restricted maximum likelihood (REML) regression.

Our study design is a primary strength of our study, given it is, to our knowledge, the first inception cohort design to assess CNS related to Mn in a well-characterized, asymptomatic cohort. The controlled nature of the welding training program and repeat full-shift personal air samples allowed us to predict subject-specific cumulative exposures at any time point, and we sampled longitudinally for both biomarkers of exposure and effect related to Mn neurotoxicity. However, we only followed subjects during the time they were in the welding training program. Over this relatively short time period, at the low-levels of exposures we observed among our young and otherwise healthy subjects, we wouldn't expect clinical indications of parkinsonism to manifest, even with sustained exposure to Mn. Because our cohort consisted of welder apprentices, exposures and work scenarios are not necessarily representative of standard occupational welding settings where exposures would be higher, more variable, and less controlled.

Several studies have reported resolution of $\mathrm{T} 1$ hyper intensities among occupationally exposed workers after removal from the source of $\mathrm{Mn}$ exposure. Despite improvement in their $\mathrm{T} 1$ imaging characteristics, clinical deficits in these workers, if present, frequently persist (40-42). This suggests while the increased T1 signal intensity is potentially reversible, there may be an exposure threshold at which the MRI changes and neurotoxic effects become permanent.

In conclusion, this study showed that even with 8-hr TWA Mn exposures at or below the ACGIH recommendations, there were increases in T1-weighted indices in the caudate, anterior and posterior putamen, and combined basal ganglia, that were significantly related to increases in cumulative $\mathrm{Mn}$ exposure among asymptomatic welder apprentices. However, there were no clinical signs of neurological dysfunction related to increases in cumulative Mn exposure at these low levels and over this relatively short time period as assessed via UPDRS3 and Grooved Pegboard. T1-weighted PI (but not other indices) has been correlated with the Grooved Pegboard (dominant hand) in one cross-sectional study, but other indices have not yet been correlated with clinical measures of parkinsonism, and toxicologically relevant reference values for 
T1-weighted indices have not yet been established for exposed persons (18). As none of our subjects exhibited clinical signs of parkinsonism we cannot address the relationship between MRI outcomes and clinical manifestations of parkinsonism with our cohort. Previously, T1-weighted MRI measures have been positively correlated with Mn exposure, though not at levels as low as in our study or with repeat measurements in a wellcharacterized inception cohort such as ours. Our study offers additional converging evidence that $\mathrm{Mn}$ exposure is associated with $\mathrm{T} 1$ signal intensity in various parts of the basal ganglia, making T1-weighted MRI (especially in the caudate/putamen) a biomarker of exposure to $\mathrm{Mn}$, seemingly sensitive across a wide range of exposure levels, and relatively short time periods.

\section{Acknowledgments}

The National Institute of Environmental Health Sciences of the National Institutes of Health Research supported research reported in this publication (award number R01ES017809). Dr. Criswell was supported by NIH career development grant K23 ES021444-01. The content is solely the responsibility of the authors and does not necessarily represent the official views of the National Institutes of Health.

\section{References}

1. Aschner M. Manganese homeostasis in the CNS. Environ Res. 1999;80(2 Pt 1):105-9. http://dx.doi.org/10.1006/ enrs.1998.3918.

2. Antonini JM, Santamaria AB, Jenkins NT, Albini E, Lucchini R. Fate of manganese associated with the inhalation of welding fumes: potential neurological effects. Neurotoxicology. 2006;27(3):304-10. http://dx.doi. $\operatorname{org} / 10.1016 /$ j.neuro.2005.09.001.

3. Guilarte TR. Manganese and Parkinson's disease: a critical review and new findings. Environ Health Perspect. 2010;118(8):1071-80. http://dx.doi.org/10.1289/ ehp.0901748.

4. Harris MK, Ewing WM, Longo W, DePasquale C, Mount $\mathrm{MD}$, Hatfield R, et al. Manganese exposures during shielded metal arc welding (SMAW) in an enclosed space. J Occup Environ Hyg. 2005;2(8):375-82. http://dx.doi. org/10.1080/15459620591007736.

5. Ellingsen DG, Dubeikovskaya L, Dahl K, Chashchin M, Chashchin V, Zibarev E, et al. Air exposure assessment and biological monitoring of manganese and other major welding fume components in welders. J Environ Monit. 2006;8(10):1078-86. http://dx.doi.org/10.1039/b605549d.
6. Smargiassi A, Baldwin M, Savard S, Kennedy G, Mergler D, Zayed J. Assessment of exposure to manganese in welding operations during the assembly of heavy excavation machinery accessories. Appl Occup Environ Hyg. 2000;15(10):746-50. http://dx.doi.org/10.1080/10473220050129383.

7. Meeker JD, Susi P, Flynn MR. Manganese and welding fume exposure and control in construction. J Occup Environ Hyg. 2007;4(12):943-51. http://dx.doi. org/10.1080/15459620701718867.

8. American Conference of Governmental Industrial Hygienists (ACGIH) Worldwide. Annual Reports of the Committees on TLVs and BEIs for Year 2013. Cincinnati, OH: ACGIH Worldwide; 2013.

9. Scientific Committee on Occupational Exposure Limits (SCOEL). Recommendation from the Scientific Committee on Occupational Exposure Limits for manganese and inorganic manganese compounds, 2011 [internet]. European Commission. Available from: http://ec.europa.eu/social/Blo bServlet?docId=6934\&langId=en. [Accessed 2 July 2014].

10. Mergler D. Neurotoxic effects of low level exposure to manganese in human populations. Environ Res. 1999;80(2 Pt 1):99-102. http://dx.doi.org/10.1006/enrs.1998.3902.

11. Roels HA, Bowler RM, Kim Y, Claus Henn B, Mergler $\mathrm{D}$, Hoet $\mathrm{P}$, et al. Manganese exposure and cognitive deficits: A growing concern for manganese neurotoxicity. Neurotoxicology. 2012;33(4):872-80. http://dx.doi. org/10.1016/j.neuro.2012.03.009.

12. Zoni S, Albini E, Lucchini R. Neuropsychological testing for the assessment of manganese neurotoxicity: a review and a proposal. Am J Ind Med. 2007;50(11):812-30. http://dx.doi. org/10.1002/ajim.20518.

13. Laohaudomchok W, Lin X, Herrick RF, Fang SC, Cavallari JM, Shrairman R, et al. Neuropsychological effects of lowlevel manganese exposure in welders. Neurotoxicology. 2011;32(2):171-9. http://dx.doi.org/10.1016/j. neuro.2010.12.014.

14. Ellingsen DG, Kusraeva Z, Bast-Pettersen R, Zibarev E, Chashchin M, Thomassen Y, et al. The interaction between manganese exposure and alcohol on neurobehavioral outcomes in welders. Neurotoxicol Teratol. 2014;41:8-15. http://dx.doi. org/10.1016/j.ntt.2013.11.004.

15. Myers JE, Thompson ML, Ramushu S, Young T, Jeebhay MF, London L, et al. The nervous system effects of occupational exposure on workers in a South African manganese smelter. Neurotoxicology. 2003;24(6):885-94. http://dx.doi. org/10.1016/S0161-813X(03)00081-0.

16. Myers JE, teWaterNaude J, Fourie M, Zogoe HB, Naik I, Theodorou $\mathrm{P}$, et al. Nervous system effects of occupational manganese exposure on South African manganese mineworkers. Neurotoxicology. 2003;24(4-5):649-56. http:// dx.doi.org/10.1016/S0161-813X(03)00035-4.

17. Dietz MC, Ihrig A, Wrazidlo W, Bader M, Jansen O, Triebig G. Results of magnetic resonance imaging in long-term manganese dioxide-exposed workers. Environ Res. 2001;85(1):37-40. http://dx.doi.org/10.1006/enrs.2000.4068. 
18. Chang Y, Woo ST, Kim Y, Lee JJ, Song HJ, Lee HJ, et al. Pallidal index measured with three-dimensional T1weighted gradient echo sequence is a good predictor of manganese exposure in welders. J Magn Reson Imaging. 2010;31(4):1020-6. http://dx.doi.org/10.1002/jmri.22104.

19. Choi DS, Kim EA, Cheong HK, Khang HS, Ryoo JW, Cho JM, et al. Evaluation of MR signal index for the assessment of occupational manganese exposure of welders by measurement of local proton $\mathrm{T} 1$ relaxation time. Neurotoxicology. 2007;28(2):284-9. http://dx.doi. org/10.1016/j.neuro.2006.05.020.

20. Criswell SR, Perlmutter JS, Huang JL, Golchin N, Flores HP, Hobson A, et al. Basal ganglia intensity indices and diffusion weighted imaging in manganese-exposed welders. Occup Environ Med. 2012;69(6):437-43. http://dx.doi.org/10.1136/ oemed-2011-100119.

21. Bowler RM, Gysens S, Diamond E, Nakagawa S, Drezgic M, Roels HA. Manganese exposure: neuropsychological and neurological symptoms and effects in welders. Neurotoxicology. 2006;27(3):315-26. http://dx.doi. $\operatorname{org} / 10.1016 /$ j.neuro.2005.10.007.

22. Levy BS, Nassetta WJ. Neurologic effects of manganese in humans: a review. Int J Occup Environ Health. 2003;9(2):15363. http://dx.doi.org/10.1179/oeh.2003.9.2.153.

23. Guilarte TR. Manganese neurotoxicity: new perspectives from behavioral, neuroimaging, and neuropathological studies in humans and non-human primates. Front Aging Neurosci. 2013;5:23. http://dx.doi.org/10.3389/fnagi.2013.00023.

24. Rabbitt P, Diggle P, Smith D, Holland F, Mc Innes L. Identifying and separating the effects of practice and of cognitive ageing during a large longitudinal study of elderly community residents. Neuropsychologia. 2001;39(5):532-43. http://dx.doi.org/10.1016/S0028-3932(00)00099-3.

25. Matthews C, Klove H. Instruction manual for the adult neuropsychology test battery. Madison, WI: University of Wisconsin Medical School; 1964.

26. Racette BA, Tabbal SD, Jennings D, Good LM, Perlmutter JS, Evanoff BA. A rapid method for mass screening for parkinsonism. Neurotoxicology. 2006;27(3):357-61. http:// dx.doi.org/10.1016/j.neuro.2005.11.005.

27. Lin YJ, Koretsky AP. Manganese ion enhances T1-weighted MRI during brain activation: an approach to direct imaging of brain function. Magn Reson Med. 1997;38(3):378-88. http:// dx.doi.org/10.1002/mrm.1910380305.

28. Baker MG, Simpson CD, Stover B, Sheppard L, Checkoway $\mathrm{H}$, Racette BA, et al. Blood manganese as an exposure biomarker: State of the evidence. J Occup Environ Hyg. 2014. http://dx.doi.org/10.1080/15459624.2013.852280.

29. Lafayette Instrument. Grooved Pegboard Test User Instructions. Lafayette, Indiana: SI Instruments; 2002.

30. Racette BA, Tabbal SD, Jennings D, Good L, Perlmutter JS, Evanoff B. Prevalence of parkinsonism and relationship to exposure in a large sample of Alabama welders. Neurology. 2005;64(2):230-5. http://dx.doi.org/10.1212/01. WNL.0000149511.19487.44.
31. Criswell S, Perlmutter J, Golchin N, Flores H, Hobson A, Aschner $\mathrm{M}$, et al. Basal ganglia intensity indices and diffusion weighted imaging in manganese-exposed welders. Occup Environ Med. 2011;68(Suppl 1):A6-A7. http://dx.doi. org/10.1136/oemed-2011-100382.19.

32. Bocca B, Alimonti A, Forte G, Petrucci F, Pirola C, Senofonte $\mathrm{O}$, et al. High-throughput microwave-digestion procedures to monitor neurotoxic elements in body fluids by means of inductively coupled plasma mass spectrometry. Anal Bioanal Chem. 2003;377(1):65-70. http://dx.doi.org/10.1007/ s00216-003-2029-4.

33. Schmidt SL, Oliveira RM, Rocha FR, Abreu-Villaca Y. Influences of handedness and gender on the grooved pegboard test. Brain Cogn. 2000;44(3):445-54. http://dx.doi. org/10.1006/brcg.1999.1204.

34. Ruff RM, Parker SB. Gender- and age-specific changes in motor speed and eye-hand coordination in adults: normative values for the Finger Tapping and Grooved Pegboard Tests. Percept Mot Skills. 1993;76(3 Pt 2):1219-30. http://dx.doi. org/10.2466/pms.1993.76.3c.1219.

35. McKnight B, Cook LS, Weiss NS. Logistic regression analysis for more than one characteristic of exposure. Am J Epidemiol. 1999;149(11):984-92. http://dx.doi.org/10.1093/ oxfordjournals.aje.a009759.

36. Pesch B, Weiss T, Kendzia B, Henry J, Lehnert M, Lotz A, et al. Levels and predictors of airborne and internal exposure to manganese and iron among welders. J Expo Sci Environ Epidemiol. 2012;22(3):291-8. http://dx.doi.org/10.1038/ jes.2012.9.

37. Bornstein R. Normative data on selected neuropsychological measures from a nonclinical sample. J Clin Psychol. 1985;41(5):651-9. http://dx.doi.org/10.1002/10974679(198509)41:5<651::AID-JCLP2270410511>3.0.CO;2-C.

38. Larsen NA, Pakkenberg H, Damsgaard E, Heydorn K. Topographical distribution of arsenic, manganese, and selenium in the normal human brain. J Neurol Sci. 1979;42(3):407-16. http://dx.doi.org/10.1016/0022-510X(79)90173-4.

39. Eriksson H, Mägiste K, Plantin L-O, Fonnum F, Hedström $\mathrm{K}-\mathrm{G}$, Theodorsson-Norheim E, et al. Effects of manganese oxide on monkeys as revealed by a combined neurochemical, histological and neurophysiological evaluation. Arch Toxicol. 1987;61(1):46-52. http://dx.doi.org/10.1007/BF00324547.

40. Nelson K, Golnick J, Korn T, Angle C. Manganese encephalopahty: utility of early magnetic resonance imaging. Br J Ind Med. 1993;50(6):510-3.

41. Huang C-C, Chu N-S, Lu C-S, Chen R-S, Calne D. Long-term progression in chronic manganism ten years of follow-up. Neurology. 1998;50(3):698-700. http://dx.doi.org/10.1212/ WNL.50.3.698

42. Yangho K. High signal intensities on T1-weighted MRI as a biomarker of exposure to manganese. Ind Health. 2004;42:111-15. http://dx.doi.org/10.2486/indhealth.42.111.

Received for publication: 2 July 2014 